\title{
AVALIAÇÃO DA ATIVIDADE ANTISSÉPTICA DE SABONETE LÍQUIDO CONTENDO EXTRATO GLICÓLICO DE FLORES DE Tagetes patula $\mathrm{L}$.
}

\section{Bruna Fabrin Somera}

Discente de Química (Bolsista de Inclusão Social Fundação Araucária); Departamento de Química, Centro de Ciências Exatas, Universidade Estadual de Londrina (UEL), Brasil.

Louise Lira Pavini

Audrey Alesandra Stinghen Garcia Lonni

Departamento de Ciências Farmacêuticas, Centro de Ciências da Saúde, Universidade Estadual de Londrina (UEL), Brasil.

Letícia Maria Krzyzaniak

Vanessa Marquito Munhoz

Gisely Cristiny Lopes

Programa de Pós-Graduação em Ciências Farmacêuticas, Universidade Estadual de Maringá (UEM), Brasil;

E-mail: giselycl@gmail.com
RESUMO: Tagetes patula L. (Asteraceae), popularmente conhecida como cravo de defunto ou cravo francês, é utilizada na medicina popular como antisséptica, depurativa do sangue e repelente de insetos. $O$ presente estudo avaliou a atividade antisséptica de sabonete líquido contendo extrato glicólico de T. patula $7,5 \%(\mathrm{p} / \mathrm{v})$. O extrato glicólico foi obtido por turbo-extração utilizando propilenoglicol e etanol $(7: 3 ; \mathrm{v} / \mathrm{v})$ a $10 \%(\mathrm{p} / \mathrm{v})$. A avaliação fitoquímica preliminar da droga vegetal indicou a presença de compostos fenólicos e teor de flavonoides de 5,73\% $\pm 0,19$ (CV = 3,33\%). Na avaliação da atividade antimicrobiana da formulação farmacêutica ocorreu a inibição do crescimento de Staphylococcus aureus na concentração avaliada.

PALAVRAS-CHAVE: Antisséptico; Atividade Antibacteriana; Flavonoides; Sabonete Líquido; Tagetes patula.

\section{ASSESSMENT OF ANTISEPTIC ACTIVITY OF LIQUID SOAP WITH GLYCOLIC EXTRACT OF TAGETES PATULA L. FLOWERS}

ABSTRACT: Tagetes patula L. (Asteraceae), or French marigold, known in Brazil as cravo-de-defunto, is used in folk medicine as antiseptic, blood thinner and insect repellent. Current study analyzes the antiseptic activity of the liquid soap with the glycolic extract of $T$. patula $7.5 \%(\mathrm{p} / \mathrm{v})$. Glycolic extract was obtained by turbo-extraction with propylenoglycol and ethanol $(7: 3 ; \mathrm{v} / \mathrm{v}) 10 \%(\mathrm{p} / \mathrm{v})$. Preliminary photochemical evaluation of the vegetal drug showed phenolic compounds and flavonoid rates at $5.73 \% \pm 0.19(\mathrm{CV}=3.33 \%)$. When the pharmaceutical formulation was evaluated for antimicrobial activity, growth inhibition of Staphylococcus aureus occurred at the assessed concentration.

KEY WORDS: Antibacterial Activity; Antiseptic; Flavonoids; Liquid Soap; Tagetes patula.

\section{INTRODUÇÃO}

Denomina-se de antissepsia às medidas propostas para inibir o crescimento ou destruir os microrganismos existentes nas camadas superficiais, microbiota transitória, ou nas camadas profundas, microbiota residente, da pele ou mucosa, por meio da aplicação de um germicida classificado como antisséptico (REIS et al., 2011).

A flora normal da superfície corporal compreende dois distintos grupos de microrganismos: a flora residente e a transiente. A 
flora normal, normalmente não patogênica, é composta por Gram-positivos, como Staphylococcus aureus e, em menor proporção, Gram-negativos, tais como: Escherichia coli, Pseudomonas aeruginosa, Klebsiella sp. (CARTURAN, 2001).

A higienização das mãos é a medida mais antiga, simples e menos dispendiosa para se prevenir a disseminação de germes e tem como finalidade remover a microbiota transitória da pele e reduzir parte da microbiota residente.

O uso de produtos naturais apresenta-se como uma alternativa viável à substituição dos antissépticos e desinfetantes sintéticos convencionais, na busca da diminuição do desenvolvimento de resistência bacteriana, uma vez que a química de produtos naturais é privilegiada, pois, ao longo de bilhões de anos de evolução das espécies, moléculas foram construídas por meio da seleção natural para serem capazes de induzir respostas específicas (SACCARO JR, 2011). Assim, muitos metabólitos secundários ou especiais se notabilizam como matérias-primas valiosas para a produção de inúmeros medicamentos antimicrobianos.

Tagetes patula L. (Asteraceae), popularmente conhecida como cravo-francês, cravo-de-defunto ou botões-de-solteirão, tem origem no México. Foi introduzida no Brasil há muitos anos, onde se aclimatou perfeitamente, tornando-se subespontânea. Tradicionalmente suas flores têm sido empregadas como antissépticas, depurativas do sangue e repelentes de insetos, folhas são utilizadas para problemas renais e em dores musculares, e as raízes e sementes como purgativas (MUNHOZ et al., 2014).

A investigação da composição química de T. patula L. revela flores e folhas ricas em terpenos (DHARMAGADDA et al., 2005; RONDÓN et al., 2006; GARG et al., 1999), flavonoides (PICCAGLIA et al., 1998; KARAWYA et al., 1996; TARPO, 1969; BANNERJEE; SESHADRI, 1956; RAO; SESHADRI, 1941), alcaloides (FAIZI; NAZ, 2002) e tiofenos (RAJASEKARAN et al., 2004; BANO et al., 2002; SÜTFELD, 1982), substâncias estas que provavelmente estejam relacionadas com as atividades biológicas relatadas até o momento, entre elas: atividade inseticida (WELLS et al., 1993), atividade nematicida (BUENA et al., 2008; KYO et al., 1990;
CHADHA, 1976), atividade larvicida (MUNHOZ et al., 2014; DHARMAGADDA et al., 2005; RAJASEKARAN et al., 2004), atividade hepatoprotetora (VASILENKO et al., 1990), atividade anti-hipertensiva (SALEEM et al., 2004), atividade anti-inflamatória (YASUKAWA; KASAHARA, 2013; KASAHARA et al., 2002), atividade antibacteriana (RONDÓN et al., 2006; SOUZA et al., 2000), atividade antiviral (ANANIL et al., 2000), atividade antifúngica (FAIZI et al., 2008; ROMAGNOLI et al., 2005; MARES et al., 2004), analgésica (FAIZI et al., 2011) e antioxidante (BHATTACHARYYA et al., 2010).

Recentemente, Moreno e colaboradores (2009) relataram significativa atividade antimicrobiana do extrato hidroalcóolico de flores de T. patula frente às cepas de Staphylococcus aureus, Staphylococcus epidermidis, Streptococcus mutans, Enterococcus faecalis, Listeria monocytogenes, Escherichia coli,Klebsiellapneumoniae, Pseudomonas aeruginosa, Salmonella typhimurium e Candida albicans.

Assim, o objetivo deste trabalho foi avaliar a atividade antisséptica de sabonete líquido desenvolvido a partir do extrato glicólico de T. patula a 7,5\% (v/p), frente a cepas de $S$. aureus.

\section{MATERIAIS E MÉTODOS}

\subsection{DROGA VEGETAL}

As flores de T. patula foram adquiridas na Casa das Flores, localizada à Rua Visconde de Mauá, 168, boxe 69 , em Londrina, Paraná, no mês de junho de 2010. A identificação botânica da espécie foi realizada pela taxonomista Profa. Dra. Ana Odete Santos Vieira, do Herbário da Universidade Estadual de Londrina. Documento taxonômico foi depositado sob o número 47.032 .

As flores foram secas em estufa de ar circulante e pulverizadas.

\subsection{SOLVENTES E REAGENTES}

Todos os solventes e reagentes utilizados apresentavam grau analítico. 


\subsection{INSTRUMENTAÇÃO}

Medições espectrofotométricas foram realizadas em um espectrofotômetro Shimadzu UV-Vis, modelo PC1650, com cubetas de quartzo QS.

\subsection{AVALIAÇÃO FÍSICO-QUÍMICA}

A determinação de perda por dessecação foi realizada de acordo com a metodologia preconizada pela Farmacopeia Brasileira (2010). Os ensaios foram realizados em triplicata.

\subsection{ANÁLISE FITOQUÍMICA PRELIMINAR}

A droga vegetal foi submetida à análise fitoquímica preliminar para deteç̧ão das principais classes de metabólitos secundários através de reações químicas clássicas que resultam no desenvolvimento de coloração e/ou precipitação, característico para cada classe de substâncias avaliadas (HARBONE, 1998; SCHENKEL; GOSMANN; ATHAYDE, 2011).

\subsection{DETERMINAÇÃO DO TEOR DE FLAVONOIDES NA DROGA VEGETAL}

Colocou-se em balão de fundo redondo de 100 $\mathrm{mL}, 0,400 \mathrm{~g}$ de droga vegetal moída, exatamente pesados, acrescidos de $1 \mathrm{~mL}$ de solução de urotropina a 0,5\%, 20 $\mathrm{mL}$ de acetona $\mathrm{R}$ e $2 \mathrm{~mL}$ de ácido clorídrico $\mathrm{R}$, aquecendo sobre manta de aquecimento, mantendo sob refluxo, por 30 minutos. Filtrou-se através de pequena quantidade de algodão para um balão volumétrico de $100 \mathrm{~mL}$. Lavouse o resíduo da droga e o algodão, em balão de fundo redondo, com duas porções de acetona de $20 \mathrm{~mL}$, sob refluxo, por $10 \mathrm{~min}$. Após resfriamento à temperatura ambiente, as soluções foram filtradas, através de algodão, para balão volumétrico de $100 \mathrm{~mL}$, completando-se o volume com acetona. Em funil de separação, foram adicionados $20 \mathrm{~mL}$ de solução acetônica, $20 \mathrm{~mL}$ de água destilada e extraída com $15 \mathrm{~mL}$ de acetato de etila $\mathrm{R}$, repetindo-se por três vezes, com porções de $10 \mathrm{~mL}$. As frações acetato de etila foram reunidas e lavadas em funil de separação com duas porções de $50 \mathrm{~mL}$ de água destilada e colocadas em balão volumétrico de $50 \mathrm{~mL}$, completando-se o volume com acetato de etila (solução mãe - SM).

Adicionou-se $1 \mathrm{~mL}$ do reagente cloreto de alumínio $2 \%$ a $10 \mathrm{~mL}$ da SM, diluindo-se a $25 \mathrm{~mL}$ com solução metanólica de ácido acético $\mathrm{R}$, denominada de solução amostra SA. Ao mesmo tempo, $10 \mathrm{~mL}$ da SM foram diluídos a $25 \mathrm{~mL}$ com solução metanólica de ácido acético R. Após 30 minutos mediu-se a absorbância da SA a $425 \mathrm{~nm}$, em cubeta com 1,0 cm de espessura contra solução comparativa (SC) (DEUTSCHES, 1994).

Os ensaios foram realizados em triplicatas.

O cálculo do teor baseia-se na absorbância específica da quercetina, segundo a fórmula:

$$
\mathrm{Q}=\frac{\text { Abs.62500 }}{500 \cdot e \cdot(100-\mathrm{t})}
$$

Onde:

$$
\begin{aligned}
& \text { Abs = Absorbância medida; } \\
& \text { e = Massa da droga em } \mathrm{g} ; \\
& \mathrm{t}=\text { Perda por dessecação }(\% ; \mathrm{p} / \mathrm{p})
\end{aligned}
$$

\subsection{PREPARO DOS EXTRATOS}

O extrato glicólico foi obtido por turbólise da droga vegetal pulverizada, na proporção de 10\% $(\mathrm{p} / \mathrm{v})$, utilizando como líquido extrator uma mistura de propilenoglicol e etanol $(3: 7 ; \mathrm{v} / \mathrm{v})$, por um período de 15 minutos, com intervalos de 5 minutos, para que a temperatura não excedesse $40{ }^{\circ} \mathrm{C}$. Após, o extrato (EGT) foi filtrado a vácuo e reservado em frasco de vidro âmbar, a temperatura ambiente.

\subsection{PREPARO DA FORMULAÇÃO}

Foram preparadas duas formulações (F) de sabonete líquido: F1 - EGT (7,5\%) e F2, que não apresentava conservante (controle).

A fórmula base do sabonete estudado foi composta pelas seguintes substâncias e concentrações: lauril éter sulfato de sódio $(20,00 \% ; \mathrm{p} / \mathrm{p})$, cocoamidopropilbetaína $(3,00 \% ; \mathrm{p} / \mathrm{p})$, dietanolamida de ácido graxo de coco (3,00\%; p/p), glicerilcocoato PEG 7 (1,00\%; p/p), ácido 
cítrico (pH 6.0 qs), água destilada (100,00 mL qsp; p/p) e cloreto de sódio (qs).

\subsection{AVALIAÇÃO DA ATIVIDADE ANTISSÉPTICA}

Com a intenção de avaliar a inibição do crescimento de microrganismos, foi aplicado o sabonete diretamente em contato com o cultivo de bactérias.

O microrganismo testado foi $S$. aureus (ATCC 6336). O cultivo de bactérias, feito em Agar Mueller Hinton, foi padronizado com PBS estéril até atingir uma turvação equivalente ao tubo 0,5 da escala de McFarland $\left(1,5 \times 10^{8}\right.$ unidades formadoras de colônias (UFC/mL).

Foram preparados dois tubos, que continham: $0,2 \mathrm{~mL}$ do cultivo bacteriano, $0,8 \mathrm{~mL}$ de soro fetal bovino diluído a $5 \%$ e $4 \mathrm{~mL}$ do sabonete líquido respectivo. Foram testadas as duas formulações (F1 e F2).

Após agitação manual por 1 minuto, $1 \mathrm{~mL}$ do conteúdo dos tubos foi plaqueado pela técnica de profundidade em Agar Infusão Cérebro e Coração (BHI), nos tempos 30 segundos, 5 e 10 minutos.

As placas foram colocadas em estufa a $37{ }^{\circ} \mathrm{C}$ "over-night".

\section{RESULTADOS E DISCUSSÃO}

A caracterização da droga vegetal passa por inúmeras determinações para se estabelecer valores ou faixas que permitam a quantificação da droga antes do preparo do extrato. Métodos químicos, físicos e físicoquímicos como determinação da perda por dessecação, quantificação do teor de substâncias ativas, entre outros, são utilizados a fim de caracterizar e padronizar o material vegetal a ser utilizado na obtenção dos extratos.

A presença de água em excesso, em drogas vegetais, promove o crescimento de bactérias, fungos ou insetos e hidrólise de constituintes. Por essa razão, limites de água são descritos para drogas vegetais, visando impedir sua deterioração (FARMACOPEIA, 2010). A perda por dessecação foi realizada com a droga seca e moída, determinando-se o teor de umidade residual, que ficou em 7,75\% $\pm 0,24(\mathrm{CV}=3,15 \%)$, valor dentro dos limites estabelecidos para drogas vegetais, que variam de 8 a 14\% de umidade para a droga seca (FARIAS et al., 2008). Este parâmetro é fundamental para se determinar a estabilidade da droga frente ao período de armazenamento. Além de ser um dado utilizado para a avaliação do teor de princípios ativos.

A análise fitoquímica preliminar foi realizada para caracterizar a composição química da droga vegetal em estudo. Os resultados revelaram a presença de metabólitos secundários fenólicos, incluindo flavonoides, cumarinas e taninos. Este resultado corrobora dados de literatura sobre a presença de flavonoides na espécie vegetal.

A determinação do teor de flavonoides na droga vegetal revelou um valor de 5,73\% $\pm 0,19$ (CV = $3,33 \%$ ), teor considerado bastante alto para esta classe de metabolitos secundários em produtos naturais. Munhoz e colaboradores (2013) relataram em trabalho anterior, teor de flavonoides na ordem de $5,24 \% \pm 0,08(1,53 \%) \mathrm{em}$ flores de T. patula. Média muito superior ao encontrado em drogas vegetais ricas em flavonoides descritas na literatura (SANTOS; BLATT, 1998; PETROVICK; MELLO, 2000; BORELLA; FONTOURA, 2002). Provavelmente, são os flavonoides que estejam relacionados com a atividade antimicrobiana encontrada nos extratos (FAIZE et al., 2008; MORENO et al., 2009), justificando, assim, a avaliação da atividade antisséptica.

Fungos e bactérias causam doenças importantes no ser humano, principalmente em pacientes imunodeficientes. Apesar da existência de antibióticos e agentes antifúngicos potentes, estão aparecendo cepas resistentes ou multirresistentes continuamente, impondo a necessidade da procura permanente a novos agentes terapêuticos.

Muitas espécies vegetais são usadas popularmente para o tratamento de diversas doenças infecciosas. Atualmente, ferramentas analíticas modernas facilitam o estudo detalhado da constituição química das plantas, o que possibilita novos parâmetros ao estudo farmacológico e microbiológico, com o possível desenvolvimento de novos agentes antimicrobianos.

Lançando-se mão ao arsenal bioquímico e molecular de drogas vegetais, as propriedades bacteriostáticas e bactericidas dos flavonoides foram mencionadas recentemente em trabalhos realizados por 
Faize et al. (2008); Cushnie e Lamb (2006); Dzoyem et al. (2013), entre outros.

Para a avaliação da atividade antisséptica do sabonete líquido, foi empregada a bactéria Gram positiva (S. aureus), por estar envolvida em doenças em pacientes imunodeficientes.

$\mathrm{Na}$ avaliação da atividade antisséptica foram testados F1 e F2. Os ensaios realizados revelaram inibição no crescimento de $S$. aureus pela F1 em todos os tempos estabelecidos no teste, sendo mais significativo em 10 minutos. F2 não inibiu o crescimento das bactérias em nenhum dos tempos avaliados.

Souza e colaboradores (2004) demonstraram que o extrato seco de Stryphnodendron adstringens, rico em substâncias fenólicas do tipo taninos condensados, incorporado a um sabonete líquido, apresentou atividade antisséptica efetiva na concentração de $100 \mathrm{mg} / \mathrm{mL}$, sendo maior que a concentração bactericida mínima obtida para o extrato seco isolado.

\section{CONCLUSÃO}

Os resultados do estudo corroboraram dados de literatura, e indicam a presença de compostos fenólicos nas flores da espécie, com predominância de flavonoides.

Neste contexto, sugere-se que o possível efeito antibacteriano encontrado na avaliação do sabonete líquido contendo $7,5 \%$ de extrato glicólico de flores de T. patula, frente a cepas de $S$. aureus, é decorrente do sinergismo entre as substâncias polifenólicas (flavonoides, taninos e cumarinas) presentes nas flores da espécie vegetal. No entanto, novos ensaios devem ser realizados para estabelecer a concentração efetiva de extrato que inibe o crescimento bacteriano.

\section{CONFLITOS DE INTERESSE}

Os autores declaram que dentro dos últimos 05 anos, e para o futuro próximo, que não possuem conflito de interesse de qualquer ordem referente ao manuscrito.

\section{AGRADECIMENTOS}

Ao Prof. Dr. João Carlos de Mello, Professor Titular de Farmacognosia do Departamento de Farmácia da Universidade Estadual de Maringá, pelo auxilio técnico. À Profa. Dra. Halha Ostrensky Saridakis, Professora de Microbiologia da Universidade Estadual de Londrina, pelo auxilio técnico. À Fundação Araucária pelo apoio financeiro.

\section{REFERÊNCIAS}

ANANIL, K.; HUDSON, J. B.; SOUZA, C.; AKPAGANAL, K.; TOWER, G. H. N.; AMASOM, J. T.; GBEASSON, M. Investigation of medicinal plants of togo for antiviral and antimicrobial activities. Pharm Biol., v. 38, n. 1, p. 40-45, 2000.

BANNERJEE, N. R.; SESHADRI, T. R. Isolation and constitution of patulitrin. Proc Mathemat Sci., v. 44, p. 284-286, 1956.

BANO, H.; AHMED, S. W.; AZHAR, I.; SHAIQ, A. M.; ALAM, N. Chemical Constituents of Tagetes patula L. Pak J Pharm Sci., v. 15, p. 1-12, 2002.

BHATTACHARYYA, S.; DATTA, S.; MALLICK, B.; DHAR, P.; GHOSH, S. Lutein Content and in Vitro Antioxidant Activity of Different Cultivars of Indian Marigold Flower (Tagetes patula L.) Extracts. J Agric Food Chem., v. 58, n. 14, p. 8259-826, 2010.

BORELLA, J. C.; FONTOURA, A. Avaliação do perfil cromatográfico e do teor de flavonóides em amostras de Baccharis trimera (Less) DC. Asteraceae (carqueja) comercializadas em Ribeirão Preto, SP, Brasil. Rev Bras Farmacogn., v. 12, p. 63-67, 2002.

BUENA, A. P.; DIEZ-ROJO, M. A.; LOPEZ-PEREZ, J. A.; ROBERTSON, L.; ESCUER, M.; BELLO, A. Screening of Tagetes patula L. on different populations of Meloidogyne. Crop Protection, v. 27, p. 96-100, 2008.

CARTURAN, G. F. Guia ABC de Microbiologia: controle microbiológico na indústria de produtos de higiene pessoal, cosméticos e perfumes. 2. ed. São Paulo: Associação Brasileira de Cosmetologia, 2001.

CHADHA, Y. R. Tagetes Linn (Compositae). Wealth of 
India, v. 10, p. 109-112, 1976.

DEUTSCHES ARZNEIBUCH. 9. ed. Sttuttgart: Wissenschaftliche, 1986.

DHARMAGADDA, V. S. S.; NAIK, S. N.; MITTAL, P. K.; VASUDEVAN, P. Larvicidal activity of Tagetes patula essential oil against three mosquito species. Bioresour Technol., v. 96, p. 1235-1240, 2006.

DZOYEM, J. P.; HAMAMOTO, H.; NGAMENI, B.; NGADJUI, B. T. Antimicrobial action mechanism of flavonoids from Dorstenia species. Drug Discov Ther., v. 7, p. 66-72, 2013.

FAIZI, S.; DAR, A.; SIDDIQI, H.; NAQVI, S.; NAZ, A.; BANO, S.; LUBNA. Bioassay-guided isolation of antioxidant agents with analgesic properties from flowers of Tagetes patula. Pharm Biol., v. 49, n. 5, p. 516-525, 2011.

FAIZI, S.; SIDDIQI, H.; BANO, S.; NAZ, A.; MAZHAR, K.; NASIM, S.; RIAZ, T.; KAMAL, S.; AHMAD, A.; KHAN, A. S. Antibacterial and Antifungal Activities of Different Parts of Tagetes patula: Preparation of Patuletin Derivatives. Pharm Biol., v. 46, n. 5, p. 309-320, 2008.

FAIZI, S.; NAZ, A. Jafrine, a novel and labile $\beta$-carboline alkaloid from the flowers of Tagetes patula. Tetrahedron, v. 58, p. 6185-6197, 2002.

FARIAS, M. R. Avaliação da qualidade de matériasprimas vegetais. In: SIMÕES, C. M. O.; SCHENKEL, E. P.; GOSMANN, G.; MELlO, J. C. P.; MENTZ, L. A.; PETROVICK, P. R. (Org.) Farmacognosia: da planta ao medicamento. 6. ed. Porto Alegre: UFRGS, Florianópolis: UFSC, 2011. p. 199-222.

FARMACOPEIA BRASILEIRA. 5. ed. Brasília: Agência Nacional de Vigilância Sanitária, ANVISA, 2010. v. 1.

GARG, S. N.; CHARLES, R.; KUMAR, S. A new acyclic monoterpene glucoside from the capitula of Tagetes patula. Fitoterapia, v. 70, p. 472-474, 1999.

HARBONE, J. B. Phytochemical methods: a guide to modern techniques of plant analysis, 2 ed. London, England: Chapman and Hall, 1998. p. 37-85.

KARAWYA, M. S.; HAMMOUDA, F. M.; ISMAIL, S. I.; ZAKI,
A. K.; NAZIF, N. M. HPLC and MS analyses of lutein-esters from Tagetes patula L. Qatar Univ Sci J, v. 16, p. 251$255,1996$.

KASAHARA, Y.; YASUKAWA, K.; KITANAKA, S.; KHAN, T. M.; EVANS, F. J. Effect of methanol extract from flower petals of Tagetes patula L. on acute and chronic inflammation model. Phytother Res., v. 16, p. 217-222, 2002.

KYO, M.; MIYAUEHI, Y.; FUJIMOTO, T.; MAYAMA, S. Production of nematocidal compounds by hairy root cultures of Tagetes patula L. Plant Cell Rep., v. 9, p. 393397, 1990.

LAMB, A. J.; CUSHNIE, T. P. T. Antimicrobial activity of flavonoids. Int J Antimicrob Agents, v. 26, p. 343-356, 2005.

MARES, D.; TOSI, B.; POLI, F.; ANDREOTTI, E.; ROMAGNOLI, C. Antifungal activity of Tagetes patula extracts on some phytopathogenic fungi: ultrastructural evidence on Pythium ultimum. Microbiol Res., v. 159, p. 295-304, 2004.

MELLO, J. C. P.; PETROVICK P. R. Quality control of Baccharis trimera (Less.) DC (Asteraceae). Hydroalcoholic extracts. Acta Farm Bonaerense, v. 19, p. 213-215, 2000.

MIMS, C. Microbiologia médica. 2. ed. São Paulo: Manole, 1999.

MORENO, F. R.; RIBEIRO, G. S.; LONNI, A. A. S. G. Efeito do extrato hidroalcoólico das flores de Tagetes Patula sobre o crescimento de microrganismos. In: CONGRESSO NACIONAL DE EXTENSÃO UNIVERSITÁRIA, ENCONTRO DE ATIVIDADES CIENTÍFICAS, UNIVERSIDADE NORTE DO PARANÁ - UNOPAR, 3., 2009, Londrina, 2009. Anais... Londrina: Unopar, 2009

MUNHOZ, V. M.; LONGHINI, R.; SILVA, T. A. P.; LONNI, A. A. S. G.; SOUZA, J. R. P.; LOPES, G. C.; MELLO, J. C. P. Estudo Farmacognóstico de flores de Tagetes patula L. (Asteraceae). Rev Fitos., v. 7, p. 225-230, 2013.

MUNHOZ, V. M.; LONGHINI, R.; SOUZA, J. R. P.; ZEQUI, J. A. C.; MELLO, E. V. S. L.; LOPES, G. C.; MELLO, J. C. P. Extraction of flavonoids from Tagetes patula: process 
optimization and screening for biological activity. Rev Bras Farmacogn., v. 24, p. 576-583, 2014.

PICCAGLIA, R.; MAROTTI, M.; GRANDI, S. Lutein and lutein ester content in different types of Tagetes patula and T. erecta. Ind Crops Products, v. 8, n. 1, p. 45-51, 1998.

RAJASEKARAN, T.; RAVISHANKAR, G. A.; REDDY, B. O. In vitro growth of Tagetes patula L. hairy roots, production of thiofhenes and its larvicidal activity. Indian $\mathbf{J}$ Biotechnol., v. 3, p. 92-96, 2004.

RAO, P. S.; SESHADRI, T. R. The colouring matter of the flowers of Tagetes patula: Isolation of a new flavonol, patuletin and its constitution. Proc Mathemat Sci., v. 14, p. 643-647, 1945.

REIS, L. M.; RABELLO, B. R.; ROSS, C.; SANTOS, L. M. R. Avaliação da atividade antimicrobiana de antissépticos e desinfetantes utilizados em um serviço público de saúde. Rev Bras Enferm., v. 64, p. 870-875, 2011.

ROMAGNOLI, C.; BRUNI, R.; ANDREOTTI, E.; RAI, M. K.; VICENTINI, C. B.; MARES, D. Chemical characterization and antifungal activity of essential oil of capita from wild Indian Tagetes patula L. J Protoplasma, v. 225, p. 57-65, 2005.

RONDÓN, M.; VELASCO, J.; HERNÁNDEZ, J.; PECHENEDA, M.; ROJAS, J.; MORALES, A.; CARMONA, J.; DÍAZ, T. Chemical composition and antibacterial activity of the essential oil of Tagetes patula L. (Asteraceae) collected from the Venezuela andes. Rev Latinoamer Quím., v. 34, p. 32-36, 2006.

SACCARO JR, N. L. A regulamentação de acesso a recursos genéticos e repartição de benefícios: disputas dentro e fora do Brasil. Ambient Soc., v. 14, p. 229-244, 2011.

SALEEM, R.; AHMAD, M.; NAZ, A.; SIDDIQUI, H.; AHMAD, S. I. Hypertensive and Toxicological Study of Citric Acid and Other Constituents from Tagetes patula Roots. Arch Pharma Res., v. 27, p. 1037-1042, 2004.

SANTOS, M. D.; BLATT, C. T. T. Teor de flavonóides e fenóis totais em folhas de Pyrostegia venusta Miers. de mata e de cerrado. Rev Bras Bot., v. 21, p. 135-140, 2000.
SCHENKEL, E. P.; GOSMANN, G.; ATHAYDE, M. L. Saponinas. In: SIMÕES, C. M. O. (Org.). Farmacognosia: da planta ao medicamento. 6. ed. Florianópolis, Porto Alegre: Ed. da UFSC; Ed. da UFRGS, 2011. p. 711-740.

SOUZA, T. M.; MOREIRA, R. R. D.; PIETRO, R. C. L. R.; ISAAC, V. L. B. Avaliação da atividade antisséptica de extrato seco de Stryphnodendron adstringens (Mart.) Coville e de preparação cosmética contendo este extrato. Rev. Bras. Farmacogn., v. 17, n. 1, p. 71-75, 2007.

SÜTFELD, R. Distribution of thiophene derivatives in different organs of Tagetes patula seedlings grown under various conditions. Planta, v. 156, p. 536-540, 1982.

TARPO, E. Flavones of Tagetes patula. Farmacia, v. 17, p. 607-616, 1969.

VASILENKO, Y. K.; BOGDANOV, A. N.; FROLOVA, L. M.; FROLOV, A. V. Hepatoprotective properties of preparations from spreading marigold. Khimico Farmatsevticheskii Zhurnal, v. 24, p. 53-56, 1990.

WELLS, C.; BERTSCH, W.; PERICH, M. Insecticidal volatiles from the marigold plant (genus Tagetes). Effect of species and sample manipulation. Chromatographia, v. 35, p. 209-215, 1993.

YASUKAWA, K.; KASAHARA, Y. Effects of Flavonoids from French Marigold (Florets of Tagetes patula L.) on Acute Inflammation Model. Int J Inflammation, v. 2013, p. 5, 2013.

Recebido em: 08 de março de 2015 Aceito em: 08 de novembro de 2015 